\title{
The prophenoloxidase system is activated during the tunic inflammatory reaction of Ciona intestinalis
}

\author{
M. Cammarata $\cdot$ V. Arizza $\cdot$ C. Cianciolo • \\ D. Parrinello • M. Vazzana • A. Vizzini • G. Salerno • \\ N. Parrinello
}

Received: 24 January 2008 / Accepted: 19 May 2008 /Published online: 1 July 2008

(C) Springer-Verlag 2008

\begin{abstract}
Phenoloxidase (PO) activity was examined in the tunic tissue of Ciona intestinalis following lipopolysaccharide (LPS) intratunic injection. Tunic homogenate supernatant (THS), assayed with the Dopa-MBTH reaction, displayed $\mathrm{Ca}^{2+}$-independent $\mathrm{PO}$ activity that was raised by LPS and further enhanced by proteases. Specific inhibitors (tropolone, phenylthiourea, diethylthiocarbamate) supported the specificity of the reaction. Assay with soybean trypsin inhibitor showed that, in the tunic, PO activation with trypsin was not significantly inhibited suggesting that proteases diverse from serine proteases were involved. In vivo experiments were carried out by injecting isosmotic medium or LPS, and THS was assayed for its PO activity. Analysis of variance of the time-course profiles showed that LPS was more effective in activating proPO. To disclose the PO response at the injured site, an assay with DopaMBTH was performed in vitro. Quinones were mainly contained in the tunic matrix enriched with inflammatory cells around the injection site. Microscopic observations and immunohistochemistry with anti-CinPO-2 antibodies showed granulocytes and unilocular refractile granulocytes containing PO, whereas few morula cells were stained. In THS zymograms (SDS-polyacrylamide gel electrophoresis), PO activity linked to $90-\mathrm{kDa}$ and $120-\mathrm{kDa}$ bands was observed as an effect of LPS injection, whereas the density of $170-\mathrm{kDa}$ PO was weak. A third presumptive PO enzyme
\end{abstract}

This work was supported by the Italian MIUR (PRIN 2004 and 2006).

M. Cammarata $\cdot$ V. Arizza $\cdot$ C. Cianciolo $\cdot$ D. Parrinello

M. Vazzana $\cdot$ A. Vizzini $\cdot$ G. Salerno $\cdot$ N. Parrinello $(\square)$

Marine Immunobiology Laboratory,

Department of Animal Biology, University of Palermo,

Via Archirafi 18,

Palermo, Italy

e-mail: nicpar@unipa.it
(CinPO-3) containing the CinPO-2 peptide was identified in the recent Ciona genome version. Presumably, LPS stimulated the production and dimerization $(120 \mathrm{kDa})$ of CinPO-3 $(66 \mathrm{kDa})$. Thus, the activated proPO system includes several POs that are distinguishable by size and that are contained and presumably released by tunic inflammatory cells and hemocytes of the pharynx bars.

Keywords Phenoloxidase - Hemocyte - Tunic . Inflammation · Lipopolysaccharide $\cdot$ SDS-polyacrylamide gel electrophoresis · Ciona intestinalis (Tunicata)

\section{Introduction}

In invertebrates, the "prophenoloxidase activating system" involved in immune responses is challenged by $\beta-1,3$ glucans or lipopolysaccharides through a limited proteolysis caused by serine proteases (Johansson and Söderhäll 1989; Söderhäll and Cerenius 1998; Pang et al. 2004). Phenoloxidase (PO) is usually synthesized as the proenzyme (prophenoloxidase, proPO) and, upon activation, plays a key role in humoral immune response and melanization processes (e.g., Söderhäll and Cerenius 1998; Cerenius and Söderhäll 2004). In the active form, $\mathrm{PO}$ is a bifunctional copper-containing redox enzyme (o-diphenol: $\mathrm{O}_{2}$ oxidoreductase, EC.14.18.1) that catalyzes the ortho-hydroxylation of monophenol (i.e., tyrosine) forming $o$-diphenol, and, then, the dehydrogenation of diphenol into $o$-quinones, which may polymerize producing melanin (Nappi and Seymur 1991). Intermediate pathway products, viz., quinones or oxygen radicals, display in vitro cytotoxic effects suggesting their involvement as effectors of defence responses (Nappi and Vass 1993; Sugumaran 1996; Nappi and Ottaviani 2000; Cammarata et al. 1997; Ballarin et al. 2002). 
In ascidians, non-self agents activate serine proteases that, in turn, converted proPO (Jackson et al. 1993) into PO, which has been shown to be involved in tunic graft rejection (Raftos et al. 1987a, 1987b, 1988), in mixed hemocyte allo- or xenogeneic reactions in vitro (Kelly et al. 1992; Fuke 1980), and in the non-fusion reaction between allo- or xenogeneic colonial ascidian partners (Ballarin et al. 1996, 2002). In addition, PO can be released by Botryllus schlosseri and Halocynthia roretzi hemocytes challenged in vitro by incompatible hemolymph serum (Ballarin et al. 1994, 1996) or following erythrocyte or yeast stimulus (Hata et al. 1998). Examination of the supernatant of Ciona intestinalis hemocyte lysate has revealed some of the properties of the enzyme (Arizza et al. 1995; Cammarata et al. 1996; Parrinello et al. 2003), and the activating effect of proteases is congruent with a proPO cascade (Jackson et al. 1993). In ascidian species, several POs differing in their molecular size have been reported, and differences have also been found between POs of $C$. intestinalis granulocytes $(188 \mathrm{kDa}$ and $74 \mathrm{kDa})$ and unilocular refringent granulocytes $(175 \mathrm{kDa}$ and $74 \mathrm{kDa})$ from the hemolymph (Parrinello et al. 2003). In this ascidian, Immesberger and Burmester (2004) have identified two cDNA sequences belonging to the arthropod hemocyanin superfamily and have reported that two hemocyanin-like proteins can act as POs, named CinPO-1 and CinPO-2 (GenBank/EMBL accession numbers AJ547813 CinPO-1 and AJ547814 CinPO-2), revealing predicted molecular masses of $92.0 \mathrm{kDa}$ and $86.9 \mathrm{kDa}$, respectively.

A strong inflammatory response, following a challenge by the injection of erythrocytes (Parrinello et al. 1984a, 1984b), foreign proteins (Parrinello 1981), or lipopolysaccharide (LPS) (Parrinello et al. 2007), has been shown in the tunic of $C$. intestinalis. After few days, depending on the injected materials, cell-mediated events cause encapsulation or tissue injury, and subsequent tunic repair (Parrinello et al. 1984a). In spite of blood vessels not being contained in the largest part of the tunic, numerous hemocytes of various types, including phagocytes, morula cells, granular amoebocytes, and unilocular refractile granulocytes (URGs), represent inflammatory cells that can degranulate. The response also includes a granulation phase with fibroblast-like hemocytes (morula cells) that express FACIT-collagen ( $\mathrm{Ci}$ typeIX-collagen 1 $\alpha$-chain; Vizzini et al. 2008), whereas inducible galectin-like molecules with interleukin- $\alpha$ epitopes (Parrinello et al. 2007) are promptly enhanced.

As in crustaceans and insects, the proPO system of tunicates could be activated by LPS at the site of injury or infection, thereby playing a role in defense responses and wound healing (Aspan et al. 1990; Aspan and Söderhäll 1991; Leonard et al. 1985). We have therefore examined the PO activity in inflamed tunic tissue of $C$. intestinalis following LPS intratunic inoculation. We demonstrate the PO involvement in the inflammatory response and suggest that, in the tunic, proteases in addition to serine-proteases may be activated by LPS. The level of PO activity is higher in tunic homogenate supernatant (THS) samples at various time points after the LPS injection, and an in vitro assay of excised inflamed tunic fragments exhibits higher PO activity localized in the tunic matrix and in most granulocytes and URGs that copiously populate the inflamed tissue. Immunohistochemical reactions with antibodies raised against a peptide identified in the CinPO-2 sequence, support the tissue localization of the enzyme. Enzyme reactions in SDS-polyacrylamide gel electrophoresis (SDSPAGE) and densitometry analysis have revealed inducible 90-kDa and 120-kDa POs, and a 170-kDa band with weak activity. The possible involvement of a presumptive CinPO3 similar to CinPO-2, as predicted by in silico analysis with BLAST (PAM 30 scoring matrix) of Ciona genome sequences (JGI V2), is discussed.

\section{Materials and methods}

\section{Tunicates}

Ascidians (7-10 cm long) were collected from Mazara del Vallo Harbor (Italy), held in refrigerated $\left(18^{\circ} \mathrm{C}\right)$ and aerated sea water (SW) in 60-1 aquaria, and fed every second day with a marine invertebrate diet (Hawaiian Marine Imports, Houston, Tex.).

\section{Preparation of THS}

Ascidians were blotted dry to remove any excess of sea water, and the tunic surface was cleaned and sterilized with ethyl alcohol. Soft tunic tissue was excised in order to avoid the presence of connective tissue and the underlyning epidermis in the sample, whereas the cuticle was resected by using a razor blade. The sample was homogenized (Ultra-Turrax, IKA) in distilled water for $3 \mathrm{~min}$ on ice. The homogenate was centrifuged at $27,000 \mathrm{~g}$ for $20 \mathrm{~min}$ at $4^{\circ} \mathrm{C}$, and the resulting supernatant (THS) was dialyzed against PBS at $4^{\circ} \mathrm{C}$, divided into aliquots, and stored at $-80^{\circ} \mathrm{C}$. Since serine proteases were used to activate the proPO cascade of THS, according to the method of Jackson et al. (1993), protease inhibitors were not added to the sample preparations.

\section{LPS injection}

LPS (Escherichia coli 055:B5) solution (1 $\mathrm{mg} / \mathrm{ml})$ was prepared in sterile SW, and $100 \mu \mathrm{l}$ of this solution $(100 \mu \mathrm{g}$ LPS per animal) was injected into the tunic tissue at the 
median body region, whereas naive ascidians and ascidians injected with $100 \mu \mathrm{l}$ sterile SW served as controls. Since blood vessels are not present in the largest part of $C$. intestinalis tunic, the LPS preparation could promptly diffuse into the neighboring tissue through the wound associated with the injection. Before the injection was carried out, the tunic surface was thoroughly cleaned and sterilized with ethyl alcohol.

\section{Assay of PO activity in THS}

PO activity was measured spectrophotometrically according to Winder and Harris (1991), by using L-Dopa (3,4dihydroxy-L-phenylalanine) as the substrate and $6 \mathrm{mM} \mathrm{3-}$ methyl-2-benzothiazolinone hydrazone hydrochloride (MBTH) as a specific reagent. Briefly, $45 \mu \mathrm{l}$ THS was incubated for $20 \mathrm{~min}$ at $20^{\circ} \mathrm{C}$ in $45-\mu$ reaction mixture containing $20 \mathrm{mM}$ L-Dopa and MBTH in distilled water (Dopa-MBTH). After the reaction, dopaquinone was detected within $60 \mathrm{~min}$ at 5 -min intervals by spectrophotometric measurement at $505 \mathrm{~nm}$. PO activity was expressed in units (Us) per minute, where $1 \mathrm{U}$ was equal to $0.001 \Delta \mathrm{A}_{505} \mathrm{~min}^{-1} \mathrm{mg}^{-1}$ protein. Since the kinetics of the reaction with Dopa-MBTH reached their highest level after 20 min incubation, the $\mathrm{U}$ value observed at that time was taken into account in all experimental approaches.

The specificity of the enzyme reaction was checked as follows. Before L-Dopa and MBTH were added, THS was incubated $\left(20 \mathrm{~min}\right.$ at $\left.20^{\circ} \mathrm{C}\right)$ with the following PO inhibitors prepared in phosphate-buffered saline (PBS; $1 \mathrm{M} \mathrm{Na}_{2} \mathrm{HPO}_{4}, 1 \mathrm{M} \mathrm{NaH}_{2} \mathrm{PO}_{4}, 1.5 \mathrm{M} \mathrm{NaCl}, \mathrm{pH}$ 7.4): 1phenyl-2-thiourea (PTU), tropolone, or diethylthiocarbamic acid (DETC) at $1 \mathrm{mM}, 100 \mathrm{mM}$, and $10 \mathrm{mM}$ final concentrations respectively. These inhibitors act by chelating the copper at the active site and are known to be the most effective PO inhibitors (Kahn 1985; Aspan et al. 1995; Klabunde et al. 1998).

Treatments of THS with divalent cations, EDTA, protease inhibitors, and LPS

To estimate the effects of divalent cations, according to a previous report (Parrinello et al. 2003) on PO activity in the hemocyte lysate supernatant (HLS), $45 \mu \mathrm{l}$ THS were incubated for $20 \mathrm{~min}$ with $45 \mu \mathrm{l}$ TRIS-buffered saline (TBS; 50 mM TRIS-HCl, $0.15 \mathrm{M} \mathrm{NaCl}$, pH 7.4) containing various concentrations of $\mathrm{CaCl}_{2}$ or $\mathrm{MgCl}_{2}(5,10,100 \mathrm{mM})$ or $10 \mathrm{mM}$ ethylenediamine-tetracetic acid (EDTA). The effect of proteases on proPO was checked by adding $45 \mu \mathrm{l}$ bovine pancreas trypsin (type III; $1 \mathrm{mg} \mathrm{ml}^{-1}$ ) solution (prepared in PBS) to the THS sample (45 $\mu \mathrm{l})$. After a 20-min incubation, $45 \mu \mathrm{l}$ of the above reaction mixture was added. The spectrophotometric measurements were compared with controls in which protease solution was substituted by $45 \mu \mathrm{l}$ PBS. To inhibit serine proteases, $45 \mu \mathrm{l}$ soybean trypsin inhibitor (STI; 1.0 or $10.0 \mathrm{mg} \mathrm{ml}^{-1}$ ) were added to $45 \mu \mathrm{l}$ THS and incubated for $10 \mathrm{~min}$ at $20^{\circ} \mathrm{C}$. The mixture was then assayed for PO activity after trypsin treatment. The effect of LPS (Escherichia coli serotype 055:B5) was checked by mixing (v/v) $45 \mu$ l LPS solution $(0.5$ or $1 \mathrm{mg}$ $\mathrm{ml}^{-1}$ ) with THS. To ascertain that LPS specifically activated PO, THS was pretreated with $1 \mathrm{mM}$ PTU, tropolone, and DETC at the above-mentioned concentrations. To show the role of serine proteases in proPO activation by LPS, THS was prepared with STI to reach a final concentration of 0.5 or $5.0 \mathrm{mg} \mathrm{ml}^{-1}$ of the inhibitor.

Each of the above listed reaction mixtures was incubated with $45 \mu \mathrm{l}$ Dopa-MBTH reaction mixture for $20 \mathrm{~min}$ at $20^{\circ} \mathrm{C}$, and PO activity estimated at $505 \mathrm{~nm}$. Reaction mixtures in which the reagent solution was substituted with an equal volume of PBS acted as controls.

\section{Electrophoresis and zymogram}

To assess the molecular size, SDS-PAGE according to Laemmli (1970) calibrated with high molecular weight range standard protein (Sigma-Aldrich (USA) was used. To identify the PO activity of the protein bands, the gels were washed twice with PBS and then incubated with MBTH according to the above-described assay. After the bands were visualized, the gels were rinsed with water, and the reaction was stopped by adding $7 \%$ acetic acid.

Densitometry analysis of the zymograms was performed by using AlphaEaseFC Stand Alone V.4.0 (Spot Density tools) software. To calculate the integrated density value (IDV), the following formula was used: sum of all the pixel values after background correction/area of the stained protein bands.

To detect THS cresolate or cathecolase activity, the method described by Nellaiappan and Vinayagam (1986) was used. Briefly, the gel was washed twice $(10 \mathrm{~min})$ with phosphate buffer, $\mathrm{pH} 8$, containing $2.5 \%$ Triton X-100, rinsed in the same buffer without detergent, and incubated with $10 \mathrm{mM}$ substrate (4-methyl catechol for cathecolase activity or tyrosine methyl ester for cresolase activity) in PBS containing $0.3 \%$ MBTH. After several rinses, the reaction was stopped with $7 \%$ acetic acid. To inhibit PO cathecolase activity, the gel was treated with $10 \mathrm{mM}$ DETC.

Preparation of anti-CinPO-2 antiserum

A peptide (11-aa, EFHNDRRNRGF, Accession no. AJ547814) from the isoform CinPO-2-deduced amino acid sequence of $C$. intestinalis PO cloned and sequenced by Immesberger and Burmester (2004) was selected by antigen-prediction programs and synthesized by Sigma-Genosys (UK). Anti-PO-2- 
peptide-specific antiserum was raised in rabbits (SigmaGenosys). To check for any sequence similarity of the chosen CinPO-2 peptide to other annotated proteins, a search with BLAST (PAM 30 scoring matrix) in Ciona genome sequences (JGI V2) and in the EMBLgene bank was carried out.

Enzyme-linked immunosorbent assays to determine anti-CiPO-2 antiserum specificity

Peptide enzyme-linked immunosorbent assay (ELISA) was performed as described by Plagemann (2005). In brief, the wells of Nunc Maxisorp ELISA plates (Nunc, Denmark) were coated overnight with the peptide dissolved in carbonate buffer, $\mathrm{pH}$ 9.6, at $10 \mu \mathrm{g} /$ well. After peptide coating, the wells were rinsed with PBS containing 0.1 (v/v) Tween 20 (PBS-T) and then incubated with blocking buffer composed of PBS, $0.5 \%$ Tween 20 , and $1 \%(\mathrm{w} / \mathrm{v})$ bovine serum albumin (BSA) at room temperature for $1 \mathrm{~h}$. They were then incubated with anti-CinPO-2 antiserum diluted $(1: 1,000-1: 6,000)$ in blocking solution or preimmune rabbit serum in blocking solution (generally 1:50-1:200) at room temperature for $1 \mathrm{~h}$. After being rinsed with PBS-T, the wells were incubated with peroxidase-conjugated anti-rabbit IgG diluted 1:1,000 in blocking solution at room temperature for $60 \mathrm{~min}$, rinsed four times with PBS-T, and then incubated with o-phenylenediamine ( $2 \mathrm{mg}$ in $0.1 \mathrm{M}$ sodium citrate, $\mathrm{pH}$ 4.0) substrate $(100 \mu \mathrm{l} / \mathrm{well})$ for $15-30 \mathrm{~min}$. The peroxidase product was quantified by measuring absorbance at $492 \mathrm{~nm}$ with an automatic plate reader.

To check for specificity of the antiserum, antibody binding to immobilized peptide was inhibited by CinPO-2 peptide in solution (competition ELISA). The peptide-coated plates were prepared as reported above; after being rinsed with PBS-T and treatment with blocking solution, the plates were incubated with a mixture containing $100 \mu \mathrm{l}$ antiserum diluted 1:3,000 or 1:5,000 in PBS-T with the peptide $(10 \mu \mathrm{g} /$ well). The wells were rinsed three times with PBS-T, and the standard procedure was used as described above.

\section{Western blot analysis}

SDS-gels were soaked in transfer buffer $(20 \mathrm{mM}$ TRIS, $150 \mathrm{mM}$ glycine, $\mathrm{pH}$ 8.8) for $10 \mathrm{~min}$, and proteins were transferred to a nitrocellulose sheet (Hybond-ECL Amersham Biosciences) by using a semi-dry apparatus (BIORAD) for $1.5 \mathrm{~h}$ at $5-10 \mathrm{~V}$ in transfer buffer. The filter was soaked for $2 \mathrm{~h}$ in blocking buffer containing $2 \%(\mathrm{w} / \mathrm{v})$ BSA and $0.05 \%(\mathrm{v} / \mathrm{v})$ Triton X-100 in PBS, then incubated with rabbit anti-CinPO2 antiserum $(1: 6,000)$ for $1 \mathrm{~h}$, washed $(4 \times)$ with blocking buffer, and incubated for $1 \mathrm{~h}$ with alkaline-phosphatase-conjugated anti-rabbit sheep $\operatorname{IgG}$ (1:15,000 in blocking buffer). Finally, the filter was washed with PBS $(4 \times 15 \mathrm{~min})$ and treated with $3 \mathrm{ml} \mathrm{5}$-bromo-4- chloro-3-indolyl phosphate/nitro blue tetrazolium (BCIP/ NBT) liquid substrate system.

In vitro MBTH reaction of tunic explants and $\mathrm{PO}$ inhibition

To check the PO contained in immediately excised tunic portions, the wet tissue was held in a plastic disc $(50 \mathrm{~mm})$ with $20 \mathrm{mM}$ Dopa and $6 \mathrm{mM}$ MBTH (final concentration) in $5 \mathrm{ml}$ SW containing 20\% alcohol (Ling et al. 2005, with minor modification) and incubated for $30 \mathrm{~min}$ at room temperature. The tunic matrix and cells were observed through the transparent tunic under bright-light microscopy (Fluovert Leitz, Wetzlar, Germany) or by Nomarski differential interference contrast optics. To ascertain the specificity of the enzyme reaction, the medium was enriched with DETC (10 $\mathrm{mM}$ final concentration) and incubated for $30 \mathrm{~min}$ at room temperature before the Dopa-MBTH mixture was added. The effect of STI was examined by adding $2 \mathrm{ml}$ STI $\left(1 \mathrm{mg} \mathrm{ml}^{-1}\right)$ for $30 \mathrm{~min}$ before the Dopa-MBTH reaction.

\section{Immunohistochemistry}

Fragments of the body wall (tunic and pharynx wall) were fixed in Bouin's solution for $24 \mathrm{~h}$, rinsed in $70 \%$ ethanol, and embedded in paraffin. Serial $6-\mu \mathrm{m}$-thick sections were prepared for immunohistochemical reaction.

Tissue sections were treated with $0.2 \%$ Triton X-100 and $0.1 \%$ Tween 20 in PBS for $30 \mathrm{~min}$. To prevent the nonspecific binding of antibodies, a treatment with $3 \%$ BSA in PBS for $90 \mathrm{~min}$ at room temperature was performed. After two washes in PBS-T, the sections were incubated overnight with anti-CinPO-2 antibodies (1:500 in PBS-T, 0.1\% BSA). Following a 90-min incubation with the secondary antibodies (1:15,000 anti-rabbit sheep IgG conjugated to alkaline phosphatase, in PBS-T, 0.1\% BSA), the sections were washed in PBS-T, treated with the specific substrate mixture (BCIP/ NBT), and after 30-60 min, mounted in distilled water.

To check whether non-specific rabbit IgGs cross-reacted with tissue components, specific antiserum was replaced by pre-immune rabbit serum. In addition, the cross-reaction of the secondary antibody was excluded by omitting the primary antibody.

Protein content determination

Protein content was estimated by the method of Bradford (1976) with BSA as a standard. THS protein content was $350 \pm 50 \mu \mathrm{g} \mathrm{ml}^{-1}$.

Statistical analysis

Unless otherwise reported, all experiments were repeated three times. The values were means of repeated assays 
performed in triplicate $( \pm \mathrm{SD})$. Significance was determined with Student's $t$-test, and differences were considered significant at $P<0.05$. Normality of the distributions and homogeneity of variances were examined by Shapiro-Wilks and Cochran tests. Once these assumptions were met $(P>0.05)$, the analysis of variance (ANOVA) was run adopting a multifactorial experimental design dealing with three main effects. Multiple comparisons were carried out with the one-way ANOVA, and the comparison among groups was performed by using Tukey's $t$-test. The Dunnet test was used to compare several treatments with the control (Dunnett 1955).

Chemicals and products

Unless otherwise reported, chemicals, products, and antibodies were from Sigma-Aldrich (USA).

\section{Results}

PO activity of THS of naive ascidians

PO activity of THS was optimally expressed at $\mathrm{pH} 7.4$, and the enzyme activity level was maintained up to $\mathrm{pH} 9.0$. Since $\mathrm{pH} 7.4$ was recorded in the THS preparations, all the assays were carried out at such a $\mathrm{pH}$. The kinetics of the reaction with Dopa-MBTH reached the highest level (20$25 \mathrm{U}$ ) after a 20-min incubation and then decreased within $60 \mathrm{~min}$. The addition of $20 \mathrm{mM} \mathrm{CaCl}{ }_{2}$ or $\mathrm{MgCl}_{2}$, or of $10 \mathrm{mM}$ EDTA did not affect the activity (data not shown).

As shown in Table 1, a low PO activity $(22.5 \pm 2.8 \mathrm{U})$ was found when THS was assayed in the absence of any activating enzyme treatment, whereas it was significantly $(P<0.001)$ raised by trypsin $(59.4 \pm 7.2 \mathrm{U} ; P<0.001)$ or chimotrypsin (39.6 $\pm 8.8 \mathrm{U} ; P<0.01)$. Accordingly, when in the presence of STI, both the trypsin and chimotrypsin effects were inhibited, PO activity was maintained at the values found by assaying the control samples with or without STI.

Treatment with LPS alone $\left(0.25\right.$ or $0.5 \mathrm{mg} \mathrm{ml}^{-1}$ final concentration) exerted an activating effect $(54.3 \pm 12.4 \mathrm{U}$ and $49.2 \pm 16.9$, respectively; $P<0.01)$ similar to that observed by using serine proteases (Table 1). The effect of LPS was maintained in the presence of 0.25 or $0.5 \mathrm{mg} \mathrm{ml}^{-1} \mathrm{STI}$. Such a result was obtained by assaying THS from 15 distinct ascidians, whether activated with the lowest or the highest LPS concentration.

The specificity of the PO reaction was demonstrated by the specific inhibitors added to THS before the activation with LPS or trypsin. As seen in Table 1, PTU, tropolone, and DETC inhibited the reaction with DETC being the most effective. The PO activity of the samples, compared with untreated or activated THS controls, was significantly lowered, and in some assays, the activity was found to be close to zero.

SW-intratunic injection enhanced THS-PO activity as revealed by time-course analysis

To examine the time course of the THS-PO activity as a response to SW injection, a sample pooled from five treated ascidians and samples from naive ascidians as controls were prepared at each time point $(0,4,8,24$, and $48 \mathrm{~h})$. Each THS sample was divided into two aliquots: the first one was assayed in the absence of trypsin, and the second
Table 1 Phenoloxidase $(P O)$ activity of tunic homogenate supernatant from naive Ciona intestinalis after various 20-min treatments (STI soybean trypsin inhibitor, PTU 1-phenyl-2-thiourea, DETC diethylthiocarbamic acid, LPS lipopolysaccharide, $P B S$ phosphate-buffered

\begin{tabular}{|c|c|c|c|}
\hline \multicolumn{2}{|l|}{ Treatment } & \multicolumn{2}{|c|}{ PO activity $\left(\Delta \mathrm{A}_{505} \mathrm{~min}^{-1} \mathrm{mg}^{-1}\right.$ protein $)$} \\
\hline & & PBS & Trypsin activated $(0.5 \mathrm{mg} / \mathrm{ml})$ \\
\hline \multicolumn{2}{|l|}{ Controls } & $22.5 \pm 2.8$ & $59.4 \pm 7.2 * * *$ \\
\hline \multicolumn{2}{|c|}{ STI $(0.5 \mathrm{mg} / \mathrm{ml})$} & $21.6 \pm 6.6$ & $28.6 \pm 2.2$ \\
\hline \multicolumn{2}{|c|}{ Chimotrypsin $(0.5 \mathrm{mg} / \mathrm{ml})$} & $39.6 \pm 8.8 * *$ & ND \\
\hline \multirow[t]{3}{*}{ PO inhibitors } & PTU (1 mM) & $14.2 \pm 5.3^{*}$ & $16.2 \pm 8.3^{* * *}$ \\
\hline & Tropolone $(100 \mathrm{mM})$ & $12.1 \pm 10.0^{* *}$ & $15.6 \pm 10.0 * * *$ \\
\hline & DETC (10 mM) & $8.2 \pm 2.3 * * *$ & $12.2 \pm 2.3 * * *$ \\
\hline \multirow[t]{4}{*}{ LPS } & LPS $(0.5$ mg/ml $)$ & $49.2 \pm 16.9 * *$ & ND \\
\hline & LPS $(0.25 \mathrm{mg} / \mathrm{ml})$ & $54.3 \pm 12.4 * *$ & \\
\hline & LPS+(STI 0.5 mg/ml) & $52.2 \pm 14.5$ & \\
\hline & LPS+(STI 5 mg/ml) & $54.3 \pm 23.0$ & \\
\hline
\end{tabular}

saline, $N D$ not done). Values are the mean of three experiments performed in triplicate $( \pm \mathrm{SD})$ and analysed for their statistical significance by Student's $t$-test $(* P<0.01, * * P<0.01, * * * P<0.001)$ 


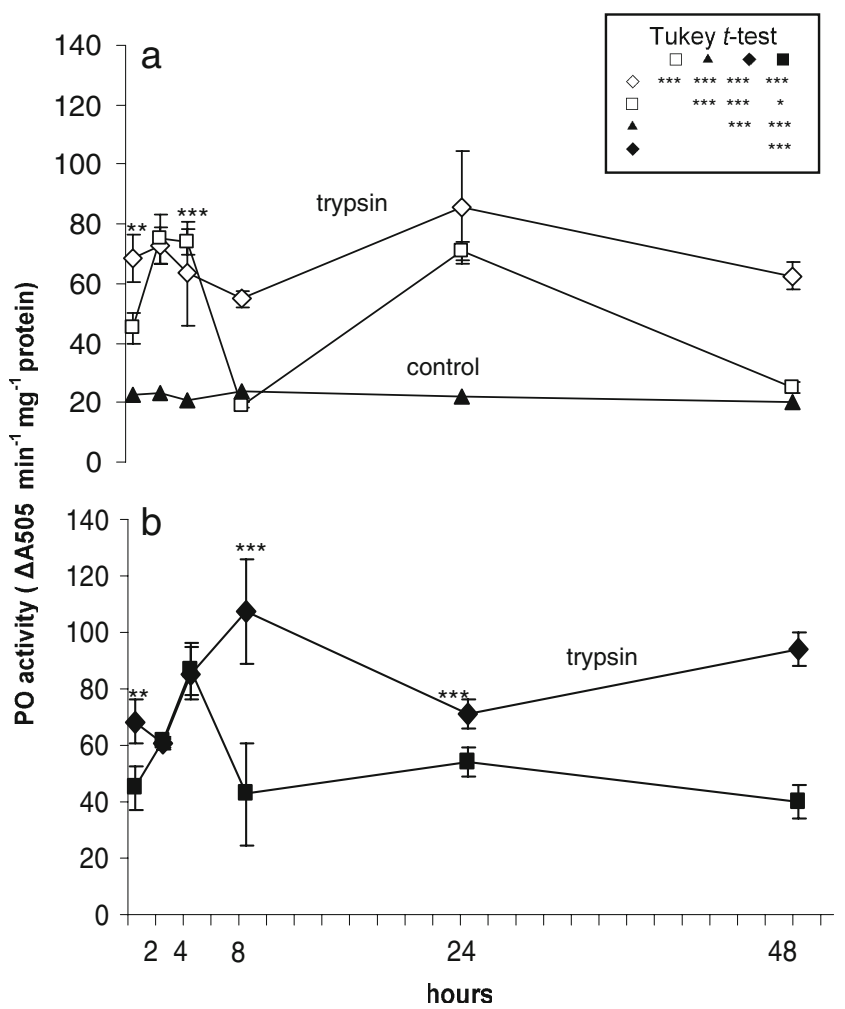

Fig. 1 Time course of tunic homogenate supernatant PO activity of Ciona intestinalis after inoculation of artificial sea water (SW) with or without LPS. a Naive ascidians (filled triangles) or injected with SW alone (open squares no trypsin treatment, open diamonds trypsin treatment). b Ascidians inoculated with $100 \mu \mathrm{g}$ LPS/ascidian (filled squares no trypsin treatment, filled diamonds trypsin treatment). Significant differences, at each time point, between LPS and SW inoculation (Dunnet $\mathrm{t}$ test) are indicated: $* P<0.05$, $* * P<0.01$, $* * * P<0.001(n=5)$. Inset: Tukey $t$-test, pair-wise comparison between LPS, SW, trypsin treatment groups, and controls

one after trypsin activation (Fig. 1; although the zero time point is indicated, 5-10 min had actually elapsed because of the need to excise the tunic portion and to prepare the THS samples). The spectophotometric values, statistically compared with each other and with the basic activity of THS controls, showed significant differences.

As shown in Fig. 1a, the PO activity increased to $40-50$ $\mathrm{U}$ (significant at $P<0.01 \mathrm{vs}$ control) when THS was prepared just after the SW inoculation and assayed without trypsin activation. In four experiments, the response profile of 100 ascidians showed that PO activity peaked at 2$4 \mathrm{~h}(70-80 \mathrm{U})$, then decreased to the control level at $8 \mathrm{~h}$, increased again at $24 \mathrm{~h}(70 \mathrm{U})$, and finally returned to the control level at $48 \mathrm{~h}$. As shown by ANOVA analysis of the time-course profiles, the PO activity of the THS samples increased as an effect of the trypsin treatment (Fig. 1a). The highest increases were recorded at 0,8 , and $48 \mathrm{~h}$, whereas at 2 and $4 \mathrm{~h}$, the activity levels did not increase, and a low not significant increment was found at $24 \mathrm{~h}$.
LPS-intratunic injection further enhanced THS-PO activity

In four separate experiments, the time-course profile of the THS-PO activity of 100 ascidians injected with LPS, although similar to that obtained after the SW injection, reached higher levels (Fig. 1b). In the absence of trypsin, PO activity was high (80-90 U) at $4 \mathrm{~h}$ and decreased to the initial level at $24 \mathrm{~h}$, when no significant differences between LPS- and SW-treated ascidians were found (Fig. 1b).

The trypsin-treated THS samples exhibited the highest PO activity when compared with the ascidians inoculated with SW (Fig. 1b). As shown by ANOVA analysis of the time-course profiles, the PO activity of the THS samples at $2,4,8 \mathrm{~h}$ increased progressively and was only significantly different at $8 \mathrm{~h}$ from the effect of the trypsin treatment, which enhanced the enzyme activity. The activity decreased at $24 \mathrm{~h}$ when its level was close to the initial one, followed by a further decrease at $48 \mathrm{~h}$.

Of note, as in the samples from the SW-inoculated ascidians, the trypsin effect was not observed at 2 and $4 \mathrm{~h}$. On the other hand, STI added to the THS samples from ascidian injected with LPS at $2-8 \mathrm{~h}$ did not significantly inhibit PO activity (Table 1).

ANOVA analysis between the time-course profiles (Fig. 1a, b) disclosed that PO activity following the LPS inoculation was significantly higher than that caused by the SW injection.

Tunic tissue treated in vitro with MBTH showed PO activity

After LPS injection, tunic tissue was excised from ascidians and directly examined by the Dopa-MBTH reaction. At 24 $48 \mathrm{~h}$ (Fig. 2a-h) after LPS injection, the tissue appeared to be stained mainly in the injury site. Pink stain in the matrix was visible through the transparent tunic, being more intense around the injection point (about $1.0 \mathrm{~cm}^{2}$; Fig. 2b). Such an intense reaction was not visible when tunic fragments were excised at $8 \mathrm{~h}$ (Fig. 2a). A weak pink stain could be observed in the tunic matrix of the SW-injected or naive ascidians. The specificity of the reaction was supported by the DETC inhibitory effect (Fig. 2d, f).

Microscopic observations showed hemocytes that densely populated the matrix, several of them being stained for their PO activity (Fig. 2e). Higher magnification disclosed that URGs and granulocytes with several granules mainly populated the inflamed tissue (Fig. $2 \mathrm{~g}, \mathrm{~h}$ ). The unique large granule of numerous URGs and granules in the cytoplasm of numerous granulocytes contained PO. Rare morula cells were positive for PO; the stain was weak and localized at the outer border of some large granules. Few stained cells were found in the tunic from SW-injected or naive ascidians (Fig. 2c). 

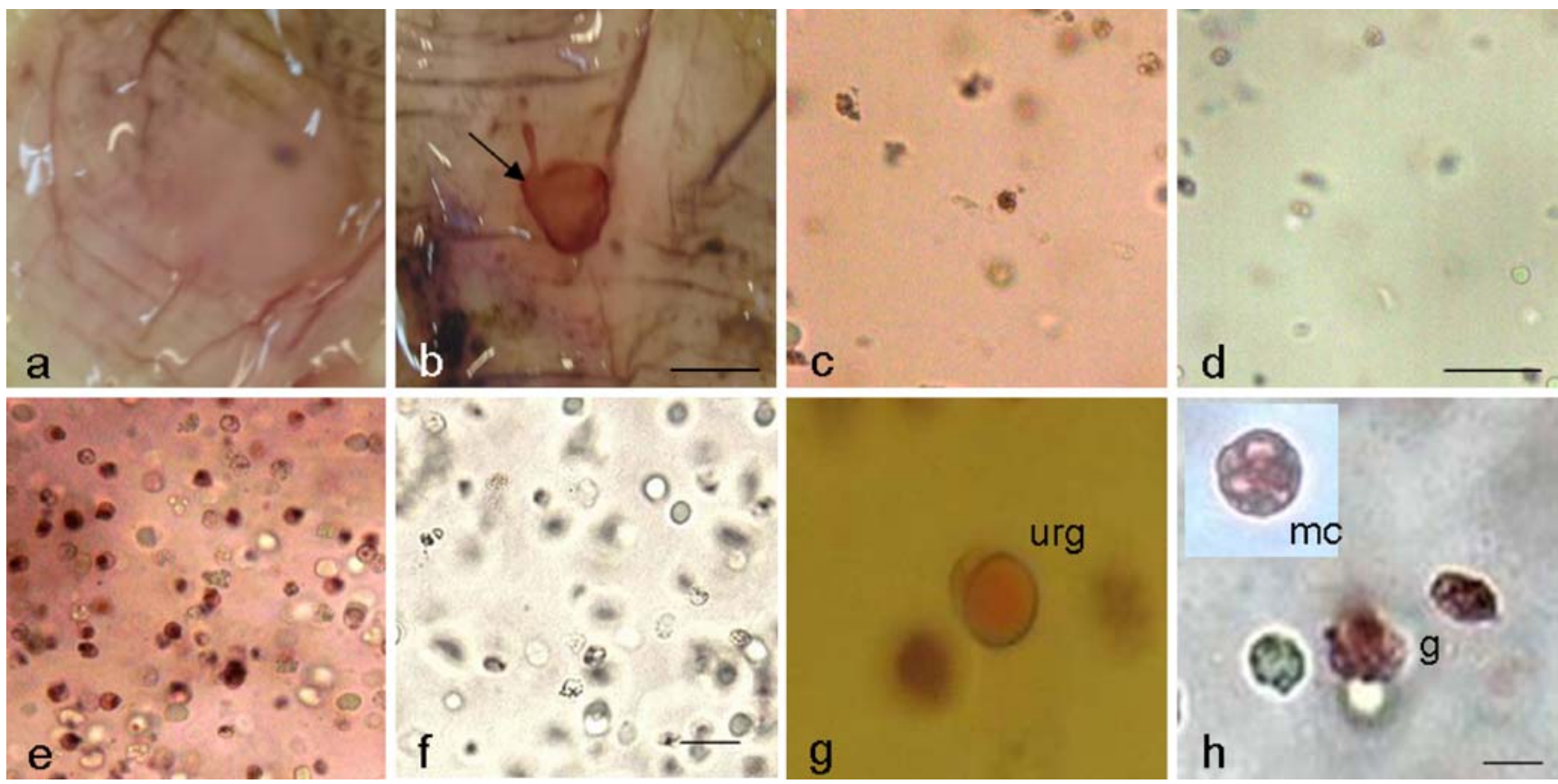

Fig. 2 Tunic fragment of Ciona intestinalis after inoculation of LPS or $\mathrm{SW}$, examined in vitro with the Dopa-MBTH reaction. a At $8 \mathrm{~h}$ after LPS inoculation. b At $24 \mathrm{~h}$ after LPS inoculation (arrow PO reaction at the injection site). c Tunic fragment at $24 \mathrm{~h}$ after SW inoculation. d Tunic fragment at $24 \mathrm{~h}$ after SW inoculation in the presence of a PO

inhibitor (DETC). e Tunic fragment at $24 \mathrm{~h}$. f Tunic fragment at $24 \mathrm{~h}$ in the presence of a PO inhibitor (DETC). $\mathbf{g}$ Higher magnification of tunic cells at $24 \mathrm{~h}$ (urg unilocular refractile granulocyte). h Higher magnification of tunic cells at $24 \mathrm{~h} \mathrm{(} m c$ morula cell, $g$ granulocyte). Bars $1.0 \mathrm{~cm}$ (a, b), $50 \mu \mathrm{m}(\mathbf{c}-\mathbf{f}, 10 \mu \mathrm{m}(\mathbf{g}, \mathbf{h})$

In silico search of a CinPO-2-peptide to produce antibodies revealed the epitope in the deduced amino acid sequence of a third form of $\mathrm{PO}$

The CinPO-2 peptide sequence, selected by antigenprediction programs and synthesized by Sigma-Genosys (UK) for raising antibodies, showed no similarity with CinPO-1. However, a search with BLAST (PAM 30 scoring matrix) of the Ciona genome (http://genome.jgi-psf.org/ Cioin2/Cioin2.home.html) identified a third sequence (Protein ID 279937) showing 39.9\% similarity with CinPO-1 and $71.6 \%$ with $\mathrm{CinPO}-2$, here temporarily indicated as CinPO-3. The final CinPO-3 sequence predicted a 1776-bp transcript (M. Cammarata et al., in preparation). The deduced protein sequence (591 amino acids), with a predicted molecular mass of $66.47 \mathrm{kDa}$, contained the amino acid peptide sequence (CinPO3 amino acids 17-27; $100 \%$ identity) used to raise the antibodies. Moreover, this peptide was not found to be similar to the known $C$. intestinalis protein sequences.

Although the peptide sequence could only be considered as indicative of the epitope structure, it supported the specificity of the antibodies that could discriminate between CinPO-1 and CinPO-2, although the possibility existed that the antibodies cross-reacted with the third form of $\mathrm{PO}$ (CinPO-3).

Specificity of the anti-PO-2 peptide antiserum

Results from ELISA and competition-ELISA supported the notion that the polyclonal antibodies were specific for the CinPO2 peptide. The highest antiserum dilution that exhibited maximum binding to immobilized peptide was 1:5,000. In addition, competitive-ELISA showed that the antiserum, diluted either $1: 3,000$ or 1:5,000, did not react with the epitope in the presence of the peptide $(10 \mu \mathrm{g} / \mathrm{well})$.

Immunohistochemical analysis with anti-CinPO-2 antibodies

Histological sections of tunic tissue and pharynx wall (Fig. 3) prepared at $24 \mathrm{~h}$ after LPS injection, when the highest hemocyte population density could be observed, were examined by immunohistochemical reaction with the anti-CinPO-2 peptide antiserum. As shown by microscopic observations, the CinPO-2 epitopes were mainly spread across the outer layer of the tunic matrix and were present in the inner part of the matrix (Fig. 3a). Unidentified hemocytes that reacted with the antibodies were found inside blood vessels of the pharynx bar (Fig. 3e,f). Antibodies also revealed CinPO-2 in traits of the bar endothelium (Fig. 3e,f). In tissue sections prepared from ascidians injected with SW, a smaller proportion of stained 

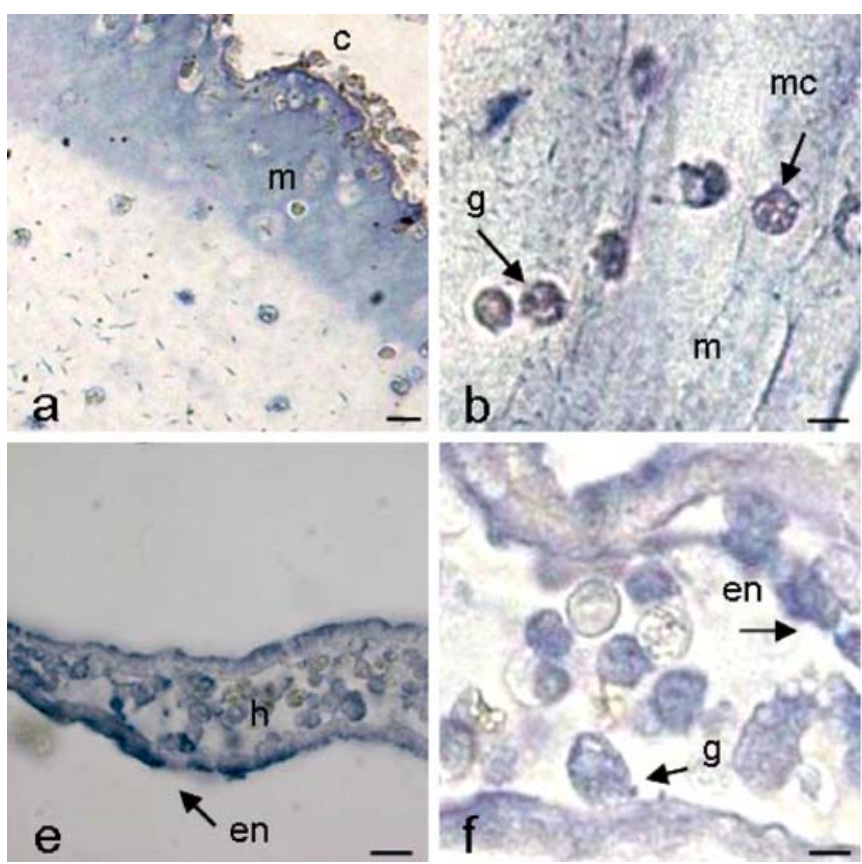

Fig. 3 Immunohistochemical CinPO2 localization with anti-CinPO-2peptide polyclonal antibodies in tunic and pharynx histological sections of Ciona intestinalis at $24 \mathrm{~h}$ after inoculation of LPS. a Tunic ( $m$ matrix, $c$ cuticle). b Higher magnification of tunic matrix and cells ( $m c$ morula cell). c Naive ascidian. d Tunic after treatment with antibodies absorbed with CinPO-2 peptide (competitive inhibi-

cells and a weak staining of the matrix were observed. In naive ascidians (Fig. 3c,g), the immunohistochemical reaction marked few tunic cells and rare hemocytes in the pharynx vessels (not shown).

Sections treated in the absence of primary antibodies or with antiserum absorbed with the peptide (competitive inhibition) supported the specificity of the antibody reaction (Fig. 3d,h).

\section{SDS-PAGE zymogram and Western blot analysis of THS}

To assess the size of the enzyme, THS prepared from ascidians at $4 \mathrm{~h}$ after LPS injection was analysed by SDSPAGE under non-reducing conditions, and the gels were treated to reveal PO (Fig. 4). The zymogram of this sample displayed the enzyme activity associated with three bands of $90 \mathrm{kDa}, 120 \mathrm{kDa}$, and $170 \mathrm{kDa}$ (Fig. 4a, lane 1), whereas, in THS from naive ascidians, only the $90-\mathrm{kDa}$ band showed PO activity (Fig. 4a, lane 3). The main $90-\mathrm{kDa}$ band was found after injection of $\mathrm{SW}$, whereas a 170-kDa band could be observed with difficulty (Fig. 4a, lane 2). The PO activity of the protein bands was not dependent on cresolase activity (Fig. 4a, lane 5; treatment with tyrosine methyl ester as substrate), whereas orthophenoloxidase activity was discovered by catechol treatment (Fig. 4, lane 4). The inhibitory effect of DETC, tropolone, and PTU supported the specificity of the enzyme in the zymogram.

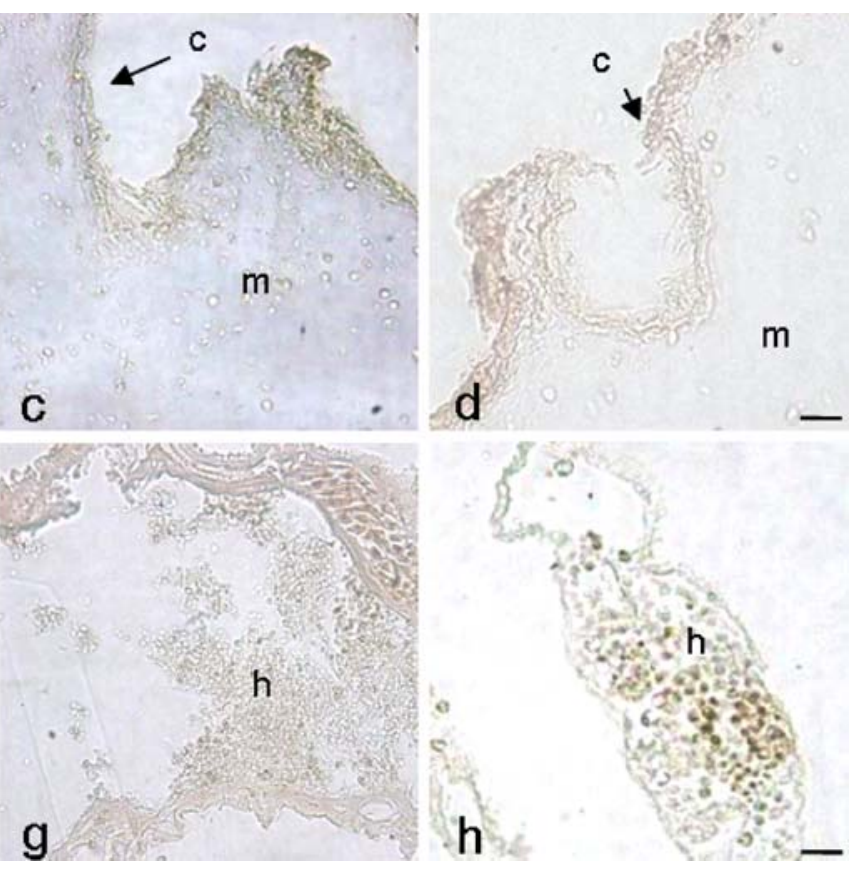

tion). e Pharynx vessel (en endothelium, $h$ hemocytes). f Higher magnification of pharynx bar ( $g$ granulocyte). $g$ Naive ascidian. h Pharynx bar after treatment with antibodies absorbed with CiPO2 peptide. Bars $20 \mu \mathrm{m}$ (a), $10 \mu \mathrm{m}$ (b), $50 \mu \mathrm{m}$ (c, d), $10 \mu \mathrm{m}(\mathbf{f}), 50 \mu \mathrm{m}$ $(\mathbf{e}, \mathbf{g}, \mathbf{h})$

The densitometry analysis of zymograms obtained by examining samples from four separate ascidians at various times after LPS injection is shown in Fig. 4b. The $90-\mathrm{kDa}$ band density was similar in THS from naive ascidians and ascidians at $2 \mathrm{~h}$ after injection, reached the highest level at $4 \mathrm{~h}$ and was low at 8,24 , and $48 \mathrm{~h}$. The low density of the $170-\mathrm{kDa}$ band was slightly enhanced at 4 and $8 \mathrm{~h}$ and then decreased to the initial level. The density of the $120-\mathrm{kDa}$ band was very low, except at 4 and $8 \mathrm{~h}$ when a small increase in its density was observed (Fig. 4a, lane 1).

Western blots of the THS proteins assayed with antiCinPO-2 antibodies revealed that only the $90-\mathrm{kDa}$ and 120-kDa bands reacted with the antibodies (Fig. 4a, lane 6). The specificity of the antibody reaction was supported by using competitive inhibition of the antibodies with the peptide (Fig. 4a, lane 7). However, a cross-reaction of antiCinPO-2 antibodies with CinPO-3 identified in silico must be taken in account.

\section{Discussion}

In Ciona intestinalis, calcium-independent PO has been found in HLS as a proenzyme activated by serine proteases, and its activity can be enhanced by microbial carbohydrates (Smith and Söderhäll 1991; Jackson et al. 1993). The effect of STI supports a model in which LPS activates serine 


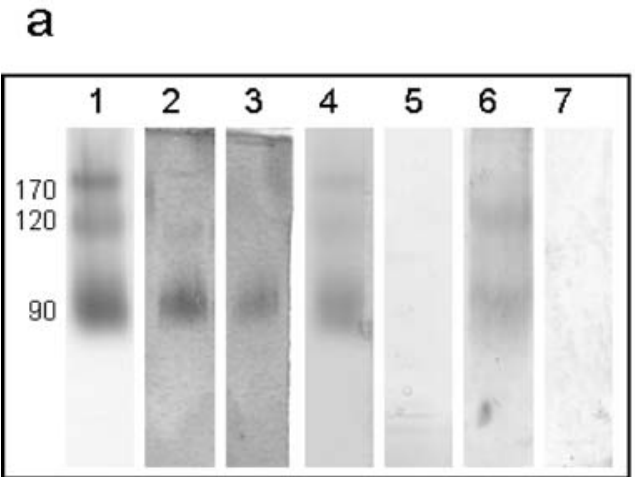

Fig. 4 SDS-polyacrylamide gel electrophoresis (SDS-PAGE; 7.5\% polyacrylamide) zymograms (lanes 1-5) and Western blots (lanes 6, 7) of Ciona intestinalis tunic homogenate supernatant (THS; $100 \mu \mathrm{g}$ protein content) after LPS or artificial sea water (SW) inoculation; bands were immunostained with anti-CinPO-2 antibodies. a Lane 1 Dopa-MBTH reaction at $4 \mathrm{~h}$ after LPS injection, lane 2 Dopa-MBTH reaction at $4 \mathrm{~h}$ after artificial SW injection, lane 3 Dopa-MBTH reaction of THS from naive ascidian, lane 4 4-methyl catechol-MBTH treatment (cathecolase activity) of THS at $4 \mathrm{~h}$ after LPS inoculation,

proteases that, in turn, activate proPO (Jackson et al. 1993). Parrinello et al. (2003) have shown, by spectrophotometric assay of HLS from separated hemocytes and by cytochemical staining, that granulocytes and URGs contained PO, whereas weak staining of the morula cells can be observed (Parrinello et al. 2001).

To study the involvement of $\mathrm{PO}$ in the $C$. intestinalis inflammatory response, we examined inflamed tissues by assaying THS at various time points after LPS intratunic inoculation. At first, the PO activity of THS from naive ascidians was assayed. The PO activity was calcium- and magnesium-independent, being optimally expressed at $\mathrm{pH}$ 7.4 after a 20-min incubation with the substrate (Dopa) and inhibited by the specific inhibitors PTU, tropolone, and DECT. The optimum $\mathrm{pH}$ coincides with the value of the THS preparations, and $\mathrm{pH} 7.0$ has been reported to be optimal for the PO activity assay of $C$. intestinalis HLSs (Smith and Söderhäll 1991). Such activity assayed in the absence of exogeneous proteases was low (about $20 \mathrm{U}$ ), and presumably the proPO activation was attributable to the tunic sample preparation. However, when trypsin or chimotrypsin was added, the PO activity increased suggesting that serine proteases activated proPO. Treatment with exogeneous trypsin raised the activity, and its action was blocked by STI; chimotrypsin had a weak effect, presumably because of its low affinity binding under our experimental conditions. Moreover, LPS was an activator, even when used at a concentration lower than that used for activating HLS, and its effect was close to that of trypsin. Similar results have been obtained by assaying HLS (Smith and Söderhäll 1991; Smith and Peddie 1992; Jackson et al. b

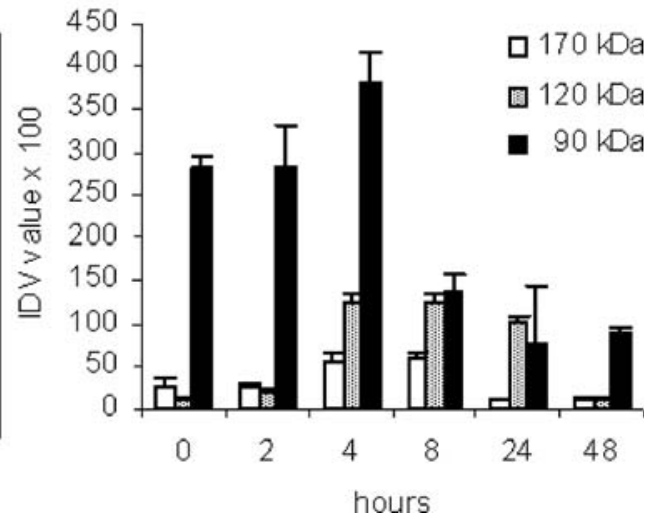

lane 5 tyrosine methyl ester-MBTH treatment (cresolase activity) of THS at $4 \mathrm{~h}$ after LPS inoculation, lane 6 Western blotting of THS with anti-CinPO2 antibodies at $4 \mathrm{~h}$ after LPS inoculation, lane 7 Western blotting with anti-PO2 antibodies incubated in the presence of CinPO2 peptide (competitive inhibition). b THS from ascidians at 2-48 $\mathrm{h}$ after LPS inoculation $(\mathrm{n}=5)$. Densitometry analysis of SDS-PAGE zymograms developed by the Dopa-MBTH reaction (IDV integrated density value: sum of all pixel values after background correction/area of the stained protein bands)

1993), and proPO activation has been reported to be dependent on LPS-activated serine proteases contained in hemocytes. However, our results on the THS are in part conflicting with this pathway. Indeed, although STI inhibits the activating effect of exogenous serine proteases in the absence of LPS, STI does not lower the enhancing effect in the presence of LPS alone. This result has also been found for LPS and STI assayed at various concentrations. Consequently, since STI is specific for serine proteases, diverse proteases could be activated by LPS in the tunic tissue. Such an activation could explain the lack of the trypsin effect in increasing the PO activity at 2 and $4 \mathrm{~h}$ and the low non-significant increase at $24 \mathrm{~h}$ after SW or LPS treatment.

According to previous reports (Parrinello et al. 2007; Vizzini et al. 2008), an inflammatory response can be obtained in vivo by intratunic injection of isosmotic medium (SW) with or without LPS (Parrinello et al. 2007). The timecourse profile obtained by assaying the THS preparations from ascidians inoculated with SW alone showed promptly (5-10 min) enhanced PO activity, followed by two peaks at $4 \mathrm{~h}$ and $24 \mathrm{~h}$. Such a response was probably attributable to the triggering of a host inflammatory reaction associated with the injection by the syringe needle and the SW inoculation. Moreover, an enhancing effect could be also caused by bacteria inadvertently being introduced into the tunic during the injection procedure.

After the LPS inoculation, a significant $(P<0.001)$ additional rise in THS-PO activity, assayed in the absence of trypsin, was observed. The time-course profile was different from the first, showing a higher PO activity, which 
peaked at $4 \mathrm{~h}$, and which was then maintained until the end of the experiment $(48 \mathrm{~h})$ at a level higher than that observed after SW injection. Exogenous trypsin in the THS samples activated the residual proPO, and this effect was mainly evident at $8 \mathrm{~h}$ and $48 \mathrm{~h}$. Statistical analysis with ANOVA of the PO activity levels generating the time-course profiles (ascidians injected with SW alone or containing LPS) demonstrated that the LPS inoculation exerted an additional inflammatory effect involving proPO system activation. Various amounts of infiltrating hemocytes that degranulate (Parrinello et al. 1990) in the inflamed tissue might explain the differences in PO activity peaks obtained by injecting diverse inflammatory agents (SW or LPS). In addition, since blood vessels are not present in examined tunic, the LPS could diffuse as an effect of the experimental wound, reaching and, probably, challenging the connective tissue and the pharynx tissues in which hemopoietic nodules are located (Ermak 1976; De Leo et al. 1987). Thus, LPS could exert a prolonged effect on the tissues, as shown by the response at $48 \mathrm{~h}$.

Surprisingly, whereas the STI inhibits exogenous trypsin activity, it is incapable of inhibiting PO activity of the THS assayed without trypsin. The possibility exists that, in the tunic, proPO activation is also dependent on proteases different from serine proteases. Further research is needed to clarify this activation pathway.

In spite of the individual variability, our results, which have been obtained by examining a large number of ascidians in four distinct experiments, strongly supported $\mathrm{PO}$ involvement in the inflammatory responses following LPS inoculation.

To check for tunic matrix and tunic cells containing PO at the reaction site, we performed an in vitro enzyme assay of the inflamed tunic tissue excised from ascidians at 24 or $48 \mathrm{~h}$ after LPS injection, when the tunic was enriched with hemocyte populations. Microscopic observations showed PO activity distributed in the tunic matrix and contained in the large granule of URGs and granules of granulocytes, whereas few morula cells were stained. This finding was in agreement with our previous report on hemocytes (Parrinello et al. 2003), whereas Smith and Peddie (1992) proposed that PO activity of HLS might be mainly attributable to morula cells contained in homogenates prepared from a separated hemocyte band in which this cell type was enriched together with vacuolated (compartment) cells. However, no cytochemical assay was carried out, and URGs were not identified in the separated hemocyte bands. These contrasting results could be a consequence of differences in hemocyte populations and activity that could characterize geographically separated ascidian populations. In addition, diversity in hemocyte type content in the hemolymph could be influenced by the season during which the animals were collected.
According to Millar (1953) and De Leo et al. (1987), test matrix, epidermis lining the matrix, and pharynx bars with blood vessels can be seen in histological sections of $C$. intestinalis body wall. Microscopic observations of wet tunic fragments after Dopa-MBTH treatment, examined through the transparent tunic, have shown a high density of the hemocyte population in the tissues inflamed by LPS. Although PO activity in cells residing in the tunic may be assumed, PO-containing hemocytes might have originated, as an effect of the LPS stimulus, from the pharynx bars (De Leo et al. 1987) and connective tissue under the epidermis (Ermak 1976). Treatment of the explants with trypsin has not been attempted, the alcohol used for weak fixation of the tissues is known to activate proPO (Ling et al. 2005).

Immunohistochemical analysis with specific anti-CinPO2 antibodies has shown that, after LPS inoculation, the enzyme is mainly distributed in the outer layer and, at a lesser extent, in the inner tunic matrix (Fig. 4a). With regard to the presumptive CinPO-3, we cannot establish whether only CinPO-2 has been identified in the sections. However, of note, following the LPS inflammatory challenge, CinPO$2 / \mathrm{CinPO} 3$ epitopes are found in the tunic tissue, in hemocytes inside the pharynx blood vessels, and in aspects of the vessel endothelium. The antibodies presumably recognize both proCinPO-2 and active $\mathrm{CinPO} 2$, and therefore, the increased immunohistochemical staining of cells (hemocytes and endothelium) in the inflamed tissues also indicate that proPO synthesis might be stimulated. On the other hand, the zymograms of THS and the in vitro tunic explant assay suggest that an increased amount of proenzyme could be activated by LPS challenge.

The above-reported results demonstrate the involvement, in tunic inflammation, of proPO/PO-containing hemocytes, which infiltrated the tissue after LPS inoculation, and can explain the second peak of activity observed ( 24 or $48 \mathrm{~h}$ ) when the time course of THS-PO activity was examined.

An attempt was carried out to identify the POs involved in the reaction. Immesberger and Burmester (2004) sequenced and cloned two PO cDNA sequences and reported that the $C$. intestinalis hemocyanin-like proteins acted as POs, named CinPO-1 and CinPO-2, with predicted molecular masses of $92.0 \mathrm{kDa}$ and $86.9 \mathrm{kDa}$, respectively. The zymogram of THS at $4 \mathrm{~h}$ after LPS injection displayed enzyme activity associated with three bands of 90,120 , and $170 \mathrm{kDa}$. The highest density $90-\mathrm{kDa}$ and $120-\mathrm{kDa}$ bands seem to be mainly related to the LPS challenge. In particular, the $120-\mathrm{kDa}$ band was weak in THS zymogram from ascidians injected with SW and was absent in THS from naive ascidians, whereas a small increase in the $170-\mathrm{kDa}$ band was observed. Oligomerization processes that could be responsible for the $120-\mathrm{kDa}$ and $170-\mathrm{kDa}$ bands, and the differences observed between THS-PO and HLS-PO (Parrinello et al. 2003) molecular sizes remain 
unclear and need further analysis. However, additional data were obtained by using Western blot analysis with antiCinPO-2 specific antibodies. As shown by the immunoblotting, only the $90-\mathrm{kDa}$ and $120-\mathrm{kDa}$ bands contained CinPO-2 epitopes. The difference between the $86.9 \mathrm{kDa}$ predicted molecular size of CinPO-2 reported by Immesberger and Burmester (2004) and the $90-\mathrm{kDa}$ band found in the THS zymogram could be attributable to the electrophoretic method used to analyze protein mass, which can be affected by the overall molecular structure. Since the zymogram did not distinguish between CinPO-1 and CinPO-2, the CinPO-2 was identified by specific antibodies. The 170-kDa band did not react with the antibodies, and therefore, the possibility exists that this band was a dimeric form of CinPO-1 (92.0 kDa), which does not contain the CinPO-2 peptide sequence used to prepare the antibodies. Unfortunately, the sequence analysis of CinPO-1 and antigen-prediction programs did not allow us to find a peptide to be used for raising antibodies specifically against CinPO-1. On the other hand, the search that we performed on Ciona intestinalis (JGI V2) revealed the sequence of a third CinPO (71.6\% similarity with CinPO-2 and 39.9\% similarity with CinPO-1) containing the peptide sequence and a deduced molecular mass of 66.5. The sizes of the $90-\mathrm{kDa}$ and $120-\mathrm{kDa}$ POs are unlikely both to contain the CinPO-2 epitope, representing monomeric and dimeric states respectively, whereas the $120 \mathrm{kDa}$ could reasonably be a dimer of the $67-\mathrm{kDa}$ PO containing the epitope as identified by the in silico search in the most recent version of Ciona genoma in which $120-\mathrm{kDa}$ CinPO-2 was not found. The inflammatory agent could induce a prompt dimerization.

In conclusion, the ascidian inflammatory response appears to be a highly complex reaction involving several cell types and factors. According to previous reports (Parrinello et al. 2007; Vizzini et al. 2008), a wound (injection procedure) and mainly LPS injection into the tunic activate a prompt pharynx inflammatory response including inducible humoral cytokine-like molecules (Parrinello et al. 2007), collagen production (Vizzini et al. 2008), and a local activation of the proPO cascade (present results). In addition, enhanced production of CinPO-2 and, presumably, of a third inducible PO (so far unknown) might be suggested.

Acknowledgements Our thanks are due to Mr. G. Miceli for collecting ascidians.

\section{References}

Arizza V, Cammarata M, Tomasino MC, Parrinello N (1995) Phenoloxidase characterization in vacuolar hemocytes from the solitary ascidians Styela plicata. J Invert Pathol 66:297-302
Aspan A, Söderhäll K (1991) Purification of prophenoloxidase from crayfish blood cells and its activation by an endogeneous serine proteinase. Insect Biochem 21:363-373

Aspan A, Sturtevant J, Smith VJ, Söderhäll K (1990) Purification and characterization of a prophenoloxidase activating enzyme from crayfish blood cells. Insect Biochem 20:709-718

Aspan A, Huang TS, Cerenius L, Söderhäll K (1995) cDNA cloning of prophenoloxidase from the freshwater crayfish Pacifastacus leniusculus and its activation. Proc Natl Acad Sci USA 92:939-943

Ballarin L, Cima F, Sabbadin A (1994) Phenoloxidase in the colonial ascidian Botryllus schlosseri (Urochordata, Ascidiacea). Anim Biol 3:41-48

Ballarin L, Cima F, Sabbadin A (1996) Morula cells and histocompatibility in the colonial ascidian Botryllus schlosseri. Zool Sci 12:757-764

Ballarin L, Cima F, Floreani M, Sabbadin A (2002) Oxidative stress induces cytotoxicity during rejection reaction in the compound ascidian Botryllus schlosseri. Comp Biochem Physiol C Toxicol Pharmacol 133:411-418

Bradford MM (1976) A rapid and sensitive method for the quantification of microgram quantities of protein utilizing the principle of protein-dye binding. Anal Biochem 72:248-254

Cammarata M, Arizza V, Vazzana M, Parrinello N (1996) Prophenoloxidase activating system in tunicate hemolymph. It J Zool 63:345-351

Cammarata M, Arizza V, Candore G, Caruso C, Parrinello N (1997) Phenoloxidase-dependent cytotoxic mechanism in ascidian Styela plicata hemocyte active against erythrocytes and K562 tumour cells. Eur J Cell Biol 74:302-307

Cerenius L, Söderhäll K (2004) The prophenoloxidase-activating system in invertebrates. Immunol Rev 198:116-126

De Leo G, Parrinello N, Di Bella MA (1987) Fine structure of blood system in Ciona intestinalis (Tunicata). Vessel and hemocytes in pharyngeal wall. Arch Biol 98:35-52

Dunnett CW (1955) A multiple comparison procedure for comparing several treatments with a control. J Am Stat Assoc 50:1096-1121

Ermak TH (1976) The hematogenic tissues of tunicates. In: Wright RK, Cooper EL (eds) Phylogeny of thymus and bone marrow-bursa cells. Elsevier/North-Holland, Amsterdam, pp 45-56

Fuke MT (1980) "Contact reactions" between xenogeneic or allogeneic coelomic cells of solitary ascidians. Biol Bull 158:304-315

Hata S, Azumi K, Yokosawa H (1998) Ascidian phenoloxidase: its release from hemocytes, isolation, characterization and physiological roles. Comp Biochem Physiol [B] Biochem Mol Biol 119:769-776

Immesberger A, Burmester T (2004) Putative phenoloxidases in the tunicate Ciona intestinalis and the origin of the arthropod hemocyanin superfamily. J Comp Physiol [B] 174:169-180

Jackson AD, Smith VJ, Peddie CM (1993) In vitro phenoloxidase activity in the blood of Ciona intestinalis and other ascidians. Dev Comp Immunol 17:97-108

Johansson MW, Söderhäll K (1989) Cellular immunity in crustaceans and proPO system. Parasitol Today 5:171-176

Kahn V (1985) Tropolone a compound that can aid in differentiating between tyrosinase and peroxidase. Biochemistry 24:915-920

Kelly K, Cooper EL, Raftos DA (1992) Purification and characterization of a humoral opsonin from the solitary urochordate Styela clava. Comp Biochem Physiol [B] 103:749-753

Klabunde T, Eicken C, Sacchettini JC, Krebs B (1998) Crystal structure of a plant catechol oxidase containing a dicopper center. Nat Struct Biol 5:1084-1090

Laemmli UK (1970) Cleavage of structural proteins during the assembly of the head of Bacteriophage T4. Nature 227:680-685

Leonard C, Söderhäll K, Ratcliffe NA (1985) Studies on prophenoloxidase and protease activity of Blaberus craniifer. Insect Biochem 15: 803-810 
Ling E, Shirai K, Kanehatsu R, Kiguchi K (2005) Reexamination of phenoloxidase in larval circulating hemocytes of the silkworm Bombyx mori. Tissue Cell 37:101-107

Millar RH (1953) Ciona. LMBC Mem Typ Br Mar Plants Anim 35: $1-123$

Nappi AJ, Ottaviani E (2000) Cytotoxicity and cytotoxic molecules in invertebrates. Bioessays 22:469-480

Nappi AJ, Seymur J (1991) Hemolyph phenoloxidases in Drosophila melanogaster, Locusta migratoria and Austropotamobius pallipes. Biochem Biophys Res Comun 180:748-754

Nappi AJ, Vass E (1993) Melanogenesis and the generation of cytotoxic molecules during insect cellular immune reactions. Pigment Cell Res 6:117-126

Nellaiappan K, Vinayagam A (1986) A rapid method for detection of tyrosinase activity in electrophoresis. Stain Technol 61:269-272

Pang Q, Zhang S, Wang C, Shi X, Sun Y (2004) Presence of prophenoloxidase in the humoral fluid of amphioxus Branchiostoma belcheri tsingtauense. Fish Shellfish Immunol 17:477-487

Parrinello N (1981) The reaction of Ciona intestinalis L. to subcuticular erythrocyte and protein injection. Dev Comp Immunol 5:105-110

Parrinello N, Patricolo E, Canicattí C (1984a) Inflammatory-like reaction in the tunic of Ciona intestinalis (Tunicata). Encapsulation and tissue injury I. Biol Bull 167:229-237

Parrinello N, Patricolo E, Canicattí C (1984b) Inflammatory-like reaction in the tunic of Ciona intestinalis (Tunicata). Encapsulation tissue injury II. Biol Bull 167:238-250

Parrinello N, De Leo G, Di Bella MA (1990) Fine structural observations of the granulocytes involved in the tunic inflammatorylike reaction of Ciona intestinalis (Tunicata). J Invert Pathol 56: 181-189

Parrinello N, Cammarata M, Vazzana M, Arizza V, Vizzini A, Cooper EL (2001) Immunological activity of ascidian hemocytes. In: Yokosawa H, Lambert CC (eds) The Biology of Ascidians. Springer, Tokyo, pp 395-401

Parrinello N, Arizza V, Chinnici C, Parrinello D, Cammarata M (2003) Phenoloxidases in ascidian hemocytes: characterization of the pro-phenoloxidase activating system. Comp Biochem Physiol [B] Biochem Mol Biol 135:583-591
Parrinello N, Arizza V, Cammarata M, Giaramita FT, Pergolizzi M, Vazzana M, Vizzini A, Parrinello D (2007) Inducible lectins with galectin properties and human IL1 $\alpha$ epitopes opsonize yeasts in the ascidian Ciona intestinalis inflammatory response. Cell Tissue Res 329:79-90

Plagemann PGW (2005) Epitope specificity of monoclonal antibodies to the N-protein of porcine reproductive and respiratory syndrome virus by ELISA with synthetic peptides. Vet Immunol Immunophatol 104:50-68

Raftos DA, Tait NN, Briscoe DA (1987a) Allograft rejection and alloimmune memory in the solitary urochordate, Styela plicata. Dev Comp Immunol 11:343-351

Raftos DA, Tait NN, Briscoe DA (1987b) Cellular basis of allograft rejection in the solitary urochordate, Styela plicata. Dev Comp Immunol 11:713-725

Raftos DA, Briscoe DA, Tait NN (1988) The mode of recognition of allogeneic tissue in the solitary urochordate Styela plicata. Transplantation 45:1123-1126

Smith VJ, Peddie CM (1992) Cell cooperation during host defense in the solitary tunicate Ciona intestinalis (L). Biol Bull 183: 211-219

Smith VJ, Söderhäll K (1991) A comparison of phenoloxidase activity in the blood of marine invertebrates. Dev Comp Immunol $15: 251-261$

Söderhäll K, Cerenius L (1998) Role of the prophenoloxidaseactivating system in invertebrate immunity. Curr Opin Immunol 10:23-28

Sugumaran M (1996) Roles of the insect cuticle in host defence reactions. In: Söderhäll K, Iwanaga S, Vasta GR (eds) New directions in invertebrates immunology. SOS, Fair Haven, pp 355-374

Vizzini A, Pergolizzi M, Vazzana M, Salerno G, Di Sano C, Macaluso P, Arizza V, Parrinello D, Cammarata M, Parrinello N (2008) FACIT collagen (1 alpha-chain) is expressed by hemocytes and epidermis during the inflammatory response of the ascidian Ciona intestinalis. Dev Comp Immunol 32:682-692

Winder J, Harris H (1991) New assays for tyrosine hydroxylase and dopa oxidase activities of tyrosinase. Eur J Biochem 198: $317-326$ 